\title{
EXPLORANDO LA VARIABILIDAD DEL REGISTRO ARQUEOLÓGICO Y TAFONÓMICO EN PALI-AIKE (CHILE) A TRAVÉS DE LA BÚSQUEDA DE REGISTROS PLEISTOCENOS A CIELO ABIERTO
}

\author{
FABIANA MARÍA MARTIN Y Y MANUEL SAN ROMÁN
}

\begin{abstract}
RESUMEN
Se presenta un diseño de búsqueda y los resultados preliminares de un trabajo destinado a evaluar la existencia de sitios finipleistocenos a cielo abierto o en lugares parcialmente expuestos pero poco explorados por arqueólogos en el Campo Volcánico Pali-Aike, Chile. Dicha búsqueda se orientó tanto en los ambientes húmedos de los ríos Chico y Gallegos Chico, como en los ambientes secos de los escoriales y antiguos aparatos volcánicos. La evidencia recuperada indica la existencia de mecanismos que funcionan como trampas colectoras de huesos en ambos ambientes, sin embargo, las cronologías de estos hallazgos se restringen -por el momento- al Holoceno.
\end{abstract}

PALABRAS CLAVES: Trampas naturales, muestreos subsuperficiales, Pleistoceno, Campo Volcánico Pali-Aike.

\section{EXPLORING THE VARIABILITY OF THE ARCHAEOLOGICAL AND TAPHONOMIC RECORDS OF PALI-AIKE (CHILE) THROUGH THE SEARCH OF OPEN AIR PLEISTOCENE RECORDS}

\section{ABSTRACT}

The search design and preliminary results of a study focused in evaluating the existence of open air fini-Pleistocene sites or partially exposed places, but scarcely explored by archaeologists, in the PaliAike Volcanic Zone, Chile, is presented. This research was oriented towards humid environments of rivers Chico and Gallegos Chico, as much as to dry locations in old scoria locations and volcanic features.

Evidence retrieved indicates the existence of mechanisms that work as bone collector tramps in both environments, nevertheless, the chronology of these findings is restricted - for the moment - to Holocene times.

KEYWORDS: natural tramps, subsurface sampling, Pleistocene, Pali-Aike Volcanic Zone. 


\section{INTRODUCCIÓN}

El objetivo de este artículo es presentar el diseño de trabajo y los resultados preliminares de una investigación focalizada en la búsqueda de sitios finipleistocenos a cielo abierto, desarrollada en el área chilena de PaliAike 1 . Para cumplir con este objetivo se utilizó una metodología de prospección destinada a la detección de un registro poco conocido y apenas contemplado por los arqueólogos (Martin y Borrero 2010, Martin et al. 2010).

El área de Pali-Aike está caracterizado por un paisaje volcánico en el que se encuentran abundantes sitios arqueológicos y paleontológicos (Sanguinetti de Bórmida 1976, Bird 1988, Massone 1981, Massone e Hidago 1981, Gómez Otero 1989-1990, Prieto 1997, Nami 1999, San Román et al. 2000, Martin et al. 2004, Barberena et al. 2007, L'Heureux 2008, entre otros). Los mismos varían tanto en tamaño como en el tipo de hallazgos y en su complejidad, pero en general comparten la característica de estar localizados en cuevas, especialmente los sitios correspondientes al Pleistoceno Tardío.

Por esta razón y para orientar la búsqueda de sitios pleistocenos a cielo abierto, se diseñó una metodología de prospección destinada a evaluar algunos rasgos topográficos de la región de Pali-Aike que pudieron tener el potencial de capturar huesos tanto en el pasado como en la actualidad. Estos rasgos, como veremos más adelante, presentan características particulares que los constituyen en verdaderas trampas naturales de huesos. A través de esta evidencia se buscó evaluar el funcionamiento que pudieron tener los mismos a fines del Pleistoceno, cuando existía una mayor diversidad faunística (Miotti y Salemme 1999). Se enfatizó la búsqueda de depósitos localizados en lugares previamente no contemplados, debido a que -como ya dijimos- la arqueología de sitios del Pleistoceno final de Patagonia básicamente se concentró en cuevas y aleros exógenos, lugares de donde procede casi la totalidad de la información conocida (Borrero 2009). Es claro que existe una alta variedad de registros potenciales a cielo abierto (Prieto 1997) o en lugares parcialmente expuestos que aún deben ser reconocidos y explorados. Entre estos últimos se destacan tubos de lava, grietas o burbujas subterráneas, rasgos formados a partir de

$1 \quad$ Proyecto FONDECYT 1070709 los distintos eventos volcánicos que conformaron al actual paisaje de Pali-Aike (Skewes 1978, D’Orazio et al. 2000). Una característica de estos rasgos es que no siempre configuran el locus ideal para la habitación humana, hecho que -para nosotros- no inhibe por un lado sus posibilidades de uso y por el otro su capacidad para entregar información novedosa. Asimismo, es necesario tener en cuenta la información obtenida en sectores tales como planicies aluviales o praderas que, si bien son difíciles de explorar, pudieron ser evaluados mediante diversas técnicas de prospección subsuperficial.

Por otra parte, buscamos evaluar la incidencia que la fauna pleistocena pudo tener en la generación de nichos carroñeros para cazadores humanos. Un objetivo importante relacionado con este tipo de búsquedas es redimensionar los posibles nichos carroñeros disponibles en el pasado, discutir el lugar que pudieron ocupar dentro de los sistemas de asentamiento prehistóricos y valorizar la variedad de situaciones culturales implementadas por las poblaciones humanas a través del tiempo. Este es un tema particularmente relevante a la hora de analizar y modelar la exploración humana inicial de Fuego-Patagonia, ya que permitirá discutir algunas de las estrategias y tácticas propuestas para esos primeros pobladores (Borrero 1999, Borrero et al. 2005, Martin 2007).

\section{ÁREA DE ESTUDIO}

Nuestro trabajo de campo se focalizó en el Campo Volcánico Pali-Aike, Chile, ubicado en el sur de la Patagonia continental con una extensión de aproximadamente $4500 \mathrm{~km}^{2}$ (Corbella 1999, 2002, D'Orazio et al. 2000). Se trabajó en particular en un sector de la cuenca de los ríos Gallegos Chico y Chico (Figura 1).

El área específica en que se concentraron las tareas comprende el tramo del curso superior del río Chico correspondiente a las estancias Brazo Norte y Cañadón Grande. Alli trabajamos extensivamente en ambas cuencas, muestreando ambientes de depositación húmedos y secos. Entre los primeros se destacan algunos rasgos geomorfológicos propios de las llanuras aluviales tales como antiguos meandros y canales formados a partir de la evolución propia del río. En los ambientes de depositación secos se exploró el escorial del Arctotherium (Figura 1), que 

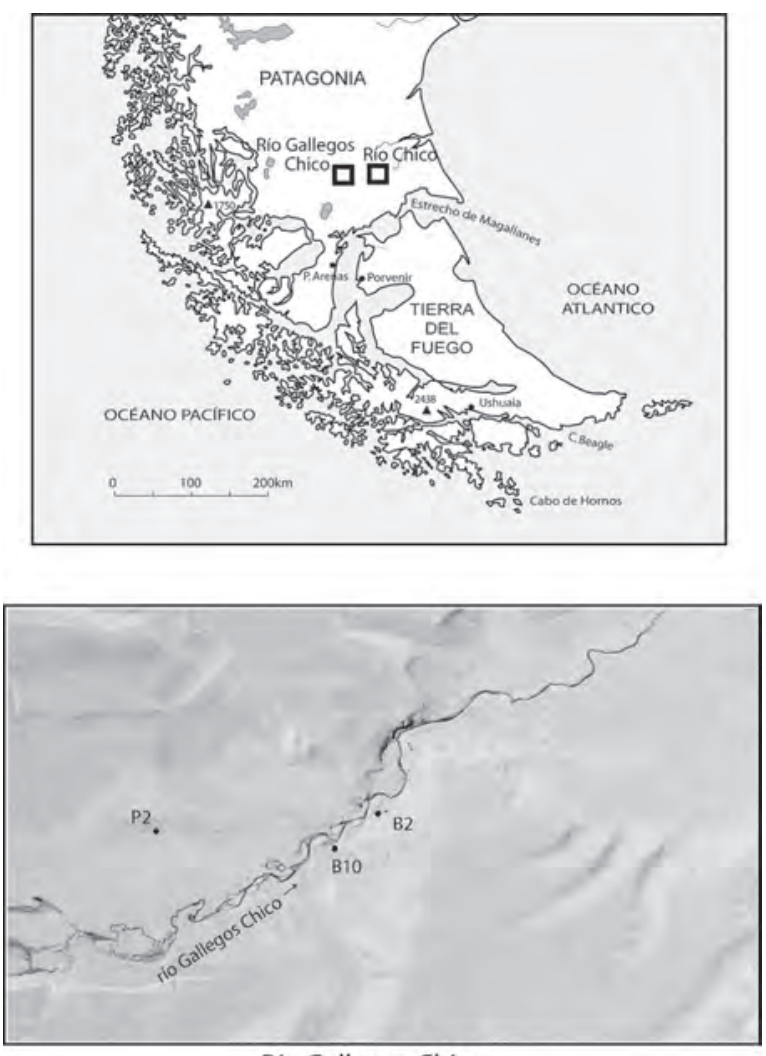

Río Gallegos Chico

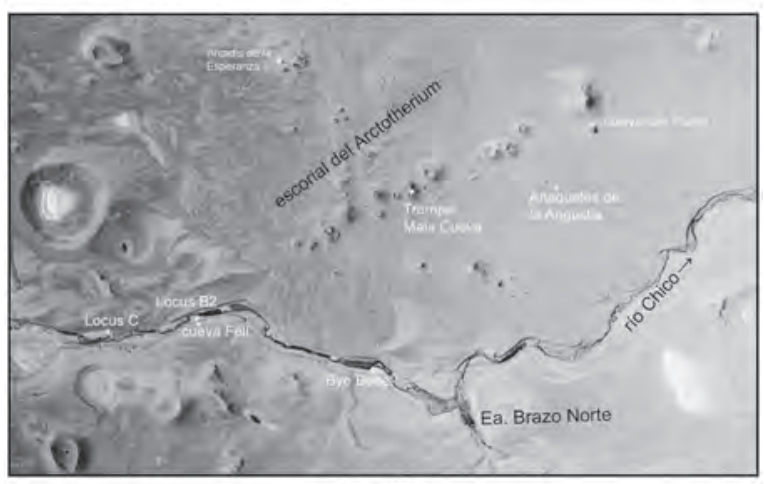

Río Chico

Fig. 1. Localización del área de estudio.

se ubica al norte del río Chico. Un poco hacia el este se ubica el cerro Donoso, en cuyas inmediaciones se ubica la cueva del Puma (19 F 432883 E, 4236267 N) (Martin et al. 2004). También fue explorada la Pampa alta al sur de cueva Fell. La investigación en este ambiente estuvo centralizada en la detección de tubos, grietas y burbujas de origen volcánicos.

\section{SUSTENTO TEÓRICO}

Las bases de nuestro trabajo son varias $e$ incluyen tanto trabajos tafonómicos naturalistas desarrollados en el Parque Nacional Torres del Paine (Borrero et al. 2005), como estudios del registro fósil (Martin 2008) y estudios preliminares de actuales trampas naturales de huesos en Monte Aymond, Argentina (Martin y Borrero 2004, 2010). Los objetivos del proyecto requierieron, entre otras cosas, la realización de trabajo tafonómico naturalista en lugares potenciales para acumular huesos.

Asumimos que todo trabajo tafonómico parte del principio del uniformismo, que sostiene que los procesos observados hoy son equivalentes a los que ocurrieron en el pasado (Binford 1981, Gifford-González 1989). Sobre la base de que este principio es válido y permite una discusión de casos del pasado, podemos sostener que la evidencia tafonómica constituye un análogo adecuado para muchas situaciones del pasado. Los casos fósiles recientemente analizados, como los de Cueva del Puma, Cueva de los Chingues y otros refuerzan la consistencia de algunas de las analogías derivadas del trabajo actualístico (Martin et al. 2004). Sabemos que existen excepciones, pero estas -básicamente relacionadas con el tempo de algunos procesos, por ejemplo la extinción de la megafauna que, por más que se acote temporalmente, como mínimo funciona en una escala de cientos de años (ver Gould 2002)- no constituyen razones para dudar de la importancia del conocimiento analógico. Por otra parte, nuestros propios trabajos han mostrado que, por ejemplo, el uso de cuevas por parte de felinos puede haber sido más importante en el pasado que lo que se aceptaba (Martin y Borrero 1997). Cuando se trabaja con categorías relacionadas con la conducta -tanto humana como animal-, de la que depende la formación de registros en distintas situaciones, se debe aceptar la existencia de una plasticidad en las respuestas posibles. En ese sentido el registro fósil cumple un papel esencial al indicar la amplitud con que puede expresarse un fenómeno, sea la capacidad de habitar en cuevas u otros habitats, o de generar depósitos que implican variable intensidad de uso. Entonces, la verdadera fuerza de esta tarea analítica está dada por la interacción entre la evidencia actual y la evidencia fósil ya que ambas se refuerzan y corrigen mutuamente. 


\section{METODOLOGÍA}

Desde el punto de vista tafonómico se realizaron, además de la búsqueda y análisis específicos de trampas naturales, transectas destinadas a evaluar el enterramiento de huesos actuales. La exploración arqueológica del escorial y de la pampa alta al sur de la cueva Fell fue intensiva, cubriendo al menos 150 km lineales de prospección ${ }^{2}$. Para la exploración de las trampas se contó con la asistencia técnica de andinistas que hicieron posible el trabajo en sitios con acceso vertical. La excavación en las trampas fue desarrollada siguiendo la estratigrafía natural de los depósitos, señalando que se debió emplear en varios casos equipo neumático para la perforación y demolición de bloques y rocas de gran talla, que constituían buena parte de la matríz sedimentaria de muchos de los yacimientos.

En el río Chico se realizaron transectas pericosteras, que utilizaron muestreos subsuperficiales, evaluando distribuciones de restos óseos en medios fluviales (ver Gutiérrez y Kaufmann 2007) y acumulaciones en cavidades profundas formadas a partir de antiguos meandros del río u otros rasgos deprimidos.

En Juni-Aike se efectuaron barrenados puntuales en antiguos meandros colmatados ubicados a distintas distancias del curso actual del río Gallegos Chico. Estos muestreos nos permitieron reubicar el sitio excavado por Prieto (1997), que posteriormente fue excavado y fechado (ver más adelante).

En el area de la cueva Fell, la búsqueda subsuperficial de depositos enterrados se efectuó utilizando barrenados al azar. Luego de la detección de depósitos de interés se implementaron muestreos sistemáticos alineados, espaciados cada 1 metro. Cuando se obtuvieron depósitos organicos fueron fechados y, sobre la base de los resultados, se seleccionó un locus para excavar. La riqueza faunística representada en Fell fue utilizada también como guía para excavar la planicie frente a la cueva. A través de estos muestreos tratamos de reconocer la extensión horizontal y vertical de los depósitos turbosos, que a la vez son indicadoras de posibles trampas para animales en el pasado y -junto a las tefras detectadas- marcadores estratigráficos.

2 Por una ancho de cobertura que varió entre los 10 y 15 metros.
El equipo de barrenos utilizado incluyo cabezales modelo DUTCH de $7 \mathrm{~cm}$ de diámetro para la descripción estratigráfica y detección de depósitos de turba. Además, se emplearon cabezales AMS de $10 \mathrm{~cm}$ de diámetro para la intersección de materiale arqueológicos.

\section{Diseño de búsqueda}

En Patagonia la técnica de barrenado ha sido empleada principalmente en otras disciplinas, tales como geología, palinología o paleoecología (Heusser 2003, Moreno et al. 2009), Sin embargo, también suele ser empleada en el desarrollo de prospecciones costeras, orientadas a la detección de conchales (Ocampo y Rivas 2000, San Román y Prieto 2004) y, en menor medida, en la arqueología de cazadores terrestres (Borrero 1986, Morello et al. 2009). El uso de barreno no sólo nos permite obtener muestras sedimentarias subsuperficiales basales sino que también nos posibilita recuperar muestras estratigráficas intactas y evaluar de manera fehaciente la distribución potencial de un depósito sepultado (Martindale et al. 2009).

Ante todo, la información cronológica derivada de los sitios pleistocenos del área (Bird 1988, Emperaire et al. 1963, San Román et al. 2000, Martin et al. 2004) nos permite inferir la existencia de depósitos faunísticos a cielo abierto de la misma antigüedad, hacia los que se orientó nuestra búsqueda. Estos conjuntos deberían ubicarse tanto en contextos fluviales, por ejemplo algunos rasgos deprimidos formados a partir de los cambios que ha sufrido el cauce del río a través del tiempo (antiguos meandros que forman grandes cavidades), como en rasgos de origen volcánico como grietas, burbujas subterráneas y tubos de lava. Tanto los rasgos de origen fluvial como los de origen volcánico muchas veces llegan a constituir depresiones o cavidades que son adecuadas para capturar huesos y/o animales completos, convirtiéndolos en verdaderas trampas naturales de restos faunísticos y/o culturales. Sin embargo, estos rasgos también deben cumplir con otros requisitos relacionados con las condiciones potenciales de preservación ósea a largo plazo. Por este motivo también se tuvieron en cuenta depósitos que pudieran tener un alto potencial de preservación, como por ejemplo algunas turberas (Bonarelli 1917) En todos los casos nuestro trabajo actualístico buscó especialmente evaluar esa capacidad de preservación. 
En términos de las posibles trampas naturales, especialmente las formadas en el campo volcánico, nuestro trabajo ha buscado comprender sus características, tales como localización, profundidad, morfología de los bordes o la existencia de plataformas de despegue que muchas veces permiten el escape de animales (Lull 1929, White et al. 1984, Wang y Martin 1993, Auler et al. 2006, Wolverton 2001, 2006). En general, las trampas suelen caracterizarse de acuerdo a las especies que capturan. En algunos casos estas suelen ser selectivas. Por ejemplo hay trampas que se caracterizan por presentar una alta proporción de carnívoros (White et al. 1984, Wolverton 2006). Otras, en cambio, se distinguen por la presencia dominante de herbívoros (Agendbroad 1984). También existen trampas de tipo "mixto", con carnívoros y herbívoros (Wang y Martin 1993). Finalmente, algunas se caracterizan por mostrar un registro óseo humano, sin artefactos, junto con uno dominado por carnívoros como por ejemplo Sima de los Huesos (España) [Arsuaga et al. 1997]. Asimismo se reconoce que la estructura de las trampas cambia a través del tiempo. Las entradas verticales u horizontales se abren y cierran a través del tiempo (Wolverton 2006). Aunque esto ocurre más frecuentemente en las de tipo kárstico que en las basalticas, también hay buenos registros de cambios en estas últimas. Estos cambios ocurren mayormente en la estructura del techo (Borrero et al. 2007).

También se tuvo en cuenta la discusión referida a la estructura de las muestras animales "capturables" por estas trampas (San Román y Martin en prep.). Temas como la selección de especies (Auler et al. 2006), la estructura de edad de los animales (Stiner et al. 1996) y otras propiedades fueron considerados tanto en función de las observaciones actualísticas de Pali-Aike, como de las expectativas generadas por las características paleobiológicas de especies extintas. Un lugar importante lo ocupa la discusión acerca de las propiedades observables en los huesos, tales como qué huesos sería esperable encontrar quebrados por caídas de rocas u otros procesos (Oliver 1989) y los tipos de fracturas u otras marcas asociados a los mismos.

\section{RESULTADOS}

Los trabajos de exploración y prospección tafonómica y arqueológica en la región de Pali-Aike han mostrado que en la actualidad existen lugares que funcionan como trampas naturales de huesos, tanto en zonas húmedas (cauce y planicie de inundación del río Chico), como secas (burbujas y tubos subterráneos en el "escorial del Arctotherium" y antiguos aparatos volcánicos).

\section{Hallazgos a cielo abierto, planicie aluvial}

Los barrenados en el área de Juni-Aike y en las inmediaciones de la cueva Fell produjeron un registro de depósitos de turbas con una cronología correspondiente a la transición Pleistoceno-Holoceno.

Una de las pruebas de barreno efectuada en la planicie aluvial del río Chico, a sólo dos metros de distancia del curso actual, nos permitió detectar sedimentos arcillosos con alto contenido orgánico, que incluía la presencia de macrovegetales enterrados a 130-140 centímetros de profundidad, con una antigüedad de $8090 \pm 40$ AP (Beta-247715).

Esta cronología mostró de manera fehaciente que existían depósitos del Holoceno temprano enterrados, lo que nos condujo a intesificar el muestreo en este sector denominado locus B2 . A través de nuevas pruebas de barreno, un poco más alejadas del río, se detectaron abundantes restos líticos que sugieren actividades relacionadas con el desbastamiento de núcleos. Estos hallazgos indicaban entonces la presencia de evidencia arqueológica fuera de la cueva, -a 44 metros de la misma- por lo tanto se procedió a efectuar un sondeo estratigráfico de $1 \mathrm{~m}^{2}$, empleando niveles artificiales de extracción de $10 \mathrm{~cm}$ de profundidad. La evidencia arqueológica mencionada, ubicada entre los 20 y $100 \mathrm{~cm}$ de profundidad, se caracteriza por abundantes lascas (con y sin corteza) y un núcleo de una misma materia prima (ś́lice). En el nivel $20-30 \mathrm{~cm}$ se registraron también espículas de ocre y carbones dispersos. Los restos óseos son muy escasos y remiten a fragmentos pequeños. Por debajo de los restos arqueológicos, entre los 120 y 130 centímetros de profundidad se recuperaron un canino superior izquierdo de Dusicyon sp., que fue fechado en $8400 \pm 50$ (Beta 259596) [Martin et al. 2010] y un incisivo de Ctenomys sp. La importancia de estos dos hallazgos radica en que los mismos se encuentran ubicados a muy pocos metros del locus $\mathrm{B} 2$, lo que nos indica la existencia de coherencia estratigráfica y cronológica. El criterio de selección para fechar el canino de zorro fue que la profundidad 


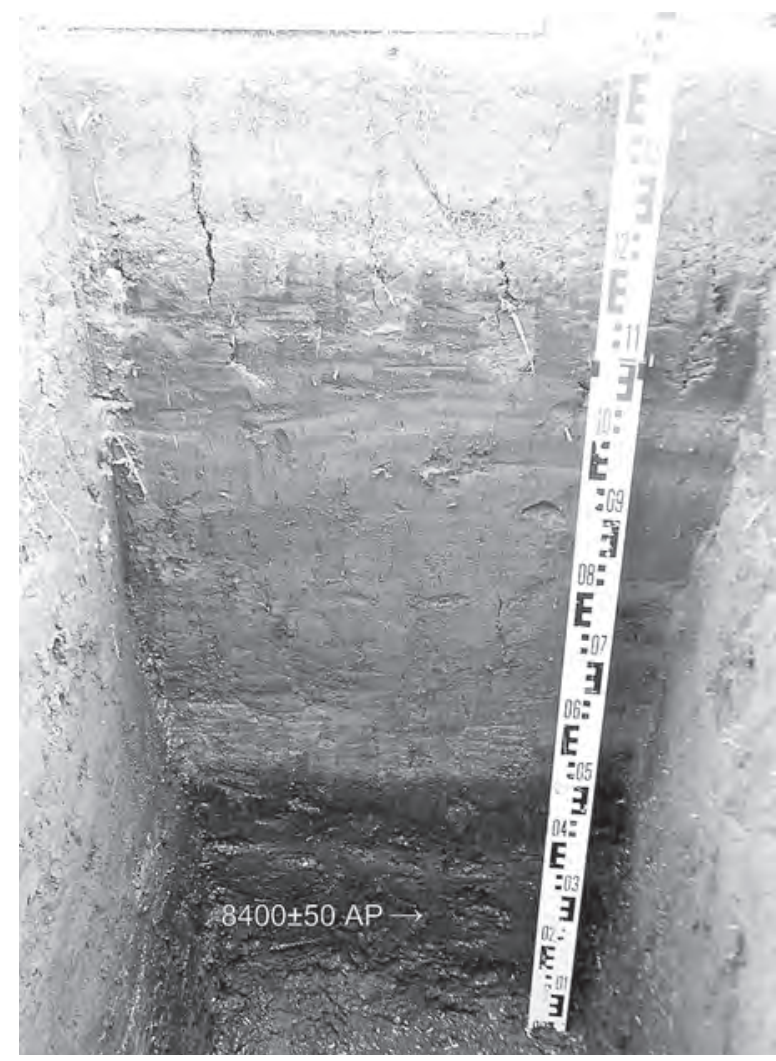

Fig. 2. Perfil sur, sondeo, Locus B2. La flecha indica el lugar de obtención y la fecha del canino de Dusicyon sp.

del hallazgo era semejante a la de la turba fechada en el locus B2, por lo tanto eran esperables cronologías semejantes e independientes, dado que los materiales fechados son distintos. A esta información se agrega la determinación de una tefra volcánica -procedente de un muestreo efectuado por French y Scaife (2009) [transecta B Borehole 2] a escasos metros de este loci (B2 y el sondeo)- aunque a mayor profundidad correspondiente a la erupción del Mt Burney MB1, cuya cronología es 8,425 \pm 500 AP (Stern com. pers., Stern 2008). En suma, distintas líneas paleoecológica y faunística indican coherencia cronológica en este sector acotado del río.
En el río Gallegos Chico, en el área de JuniAike, se efectuaron prospecciones subsuperficiales para profundizar los estudios de Prieto quien habia obtenido una cronología de 12,800 \pm 100 AP (Gif-10237) (Prieto 1997: 143) para una turba enterrada a 190 centímetros de profundidad, a la que suprayacia un deposito de tefra no identificado. Estos hallazgos fueron de gran interés debido a que remiten a una cronología finipleistocena, por lo que decidimos intensificar nuestra busqueda en ambas márgenes del río mediante barrenados y pruebas de pala. De las muestras extraídas mediante estas técnicas seleccionamos cuatro para realizar dataciones radiocarbónicas (ver tabla 1 ).

Las muestras $\mathrm{B} 2$ y $\mathrm{B} 10$ proceden de distintos loci ubicados en la margen derecha del río Gallegos Chico. El barrenado 2 (B2) se realizó en un sector alto, en las inmediaciones de un meandro antiguo. Fue necesario efectuar un muestreo subsuperficial intensivo para ubicar el locus muestreado por Prieto (1997). Creemos que el mismo corresponde a nuestra prueba de barreno B10 efectuada en un sector erosionado (probablemnete una antigua terraza del río), donde encontramos abundante material arqueológico en superficie. B10 se caracteriza por una secuencia estratigráfica de 180 centímetros de potencia que hacia la base $(105-118 \mathrm{~cm})$ exhibe un nivel de tefra -identificada por Stern como procedente del volcán Reclús-, cuyo espesor varía entre unos pocos milímetros y $10 \mathrm{~cm}$ (Figura 3). Inmediatamente por debajo de la misma se sitúa una densa capa de turba de al menos unos 50 centímetros cuyo techo fue fechado en $12,800 \pm 60$ AP (Beta-247712) a los 119-135 centímetros de profundidad. La base, ubicada a 170-180 centímetros fue fechada en 14,130 \pm 50 AP (Beta-247713) [Martin et al. 2010] (ver tabla 1). La cronología de la turba ahora obtenida reproduce casi puntualmente la obtenida por Prieto (1997), mostrando coherencia estratigráfica en este sector de la cuenca.

Tabla 1. Resultados cronológicos de turbas subsuperficiales obtenidas mediante pruebas de barrenos y pruebas de palas en el río Gallegos Chico.

\begin{tabular}{|l|l|l|l|l|}
\hline \multicolumn{1}{|c|}{ Muestra } & \multicolumn{1}{c|}{ Profundidad } & \multicolumn{1}{c|}{ Cronología AP } & \multicolumn{1}{c|}{ Sigla } & \multicolumn{1}{c|}{ Material } \\
\hline Barrenado 2 & $160-170 \mathrm{~cm}$ & $9500 \pm 50$ & Beta -247711 & Turba \\
\hline Barrenado 10 (B10) & $140-150 \mathrm{~cm}$ & $12,800 \pm 60$ & Beta -247712 & Turba \\
\hline Barrenado 10 (B10) & $180-190 \mathrm{~cm}$ & $14,130 \pm 50$ & Beta -247713 & Turba \\
\hline Pozo de pala 2 (P2) & $53 \mathrm{~cm}$ & $5330 \pm 40$ & Beta -247714 & Turba \\
\hline
\end{tabular}




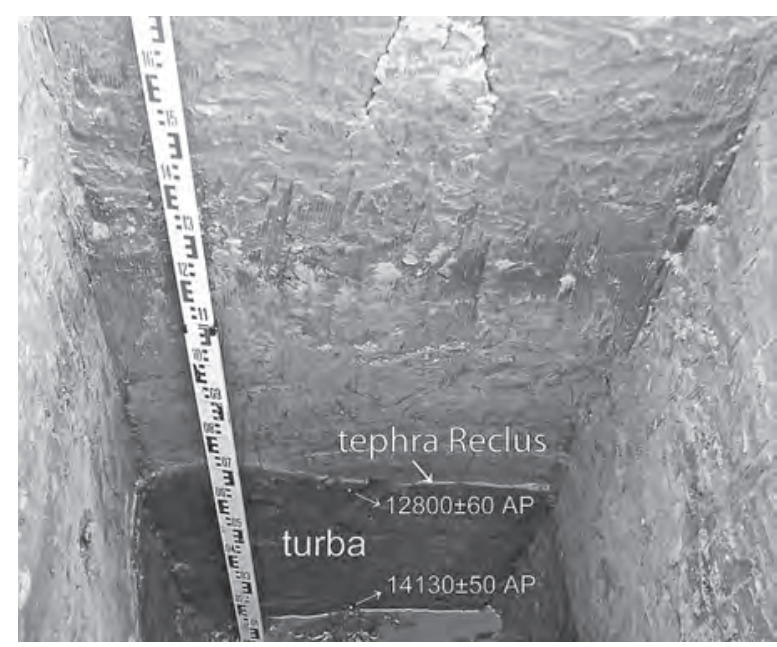

Fig. 3. Perfil este de la excavación en Juni-Aike. Las flechas señalan el nivel de tefra procedente del volcán Reclus y el nivel de turba subyacente al mismo con las cronologías asociadas.

Es importante destacar la potencia que presenta esta capa de turba, así como la composición casi exclusiva de restos macrovegetales. Las características de esta turba (y de otras muestreadas en esta localidad) difieren notablemente con respecto a las turbas del río Chico. Estas últimas, en general están compuestas por sedimentos arcillosos muy orgánicos con proporciones menores de macrovegetales y no presentan la potencia y extensión que parecen presentar las de Juni-Aike. Será necesario explorar algunas de las características aquí mencionadas debido a las implicacias que se desprenden de cada una de ellas.

Mediante una prueba de pala -P2- (tabla 1) se obtuvo una muestra de turba que se recuperó en un sector asociado a un segmento del cauce. El mismo podría tratarse de meandro antiguo, ubicado sobre la margen izquierda del río, a $540 \mathrm{~m}$ del curso actual. Es un lugar drenado, con vegetación actual de gramíneas. Esta muestra es interesante porque se encuentra localizada a 540 metros de distancia del cauce actual, por lo tanto, este fechado es un indicador de las fluctuaciones del cauce del río en los últimos 5000 años.

En cuanto al registro tafonómico actual, en las inmediaciones de la cueva Fell; se destaca la escasez de restos óseos concentrados. Sólo hemos detectado una cavidad profunda de aproximadamente 7 metros de diámetro y al menos $1,74 \mathrm{~m}$ de profundidad, formada a partir de un antiguo meandro del río ( $\mathrm{Fi}^{-}$

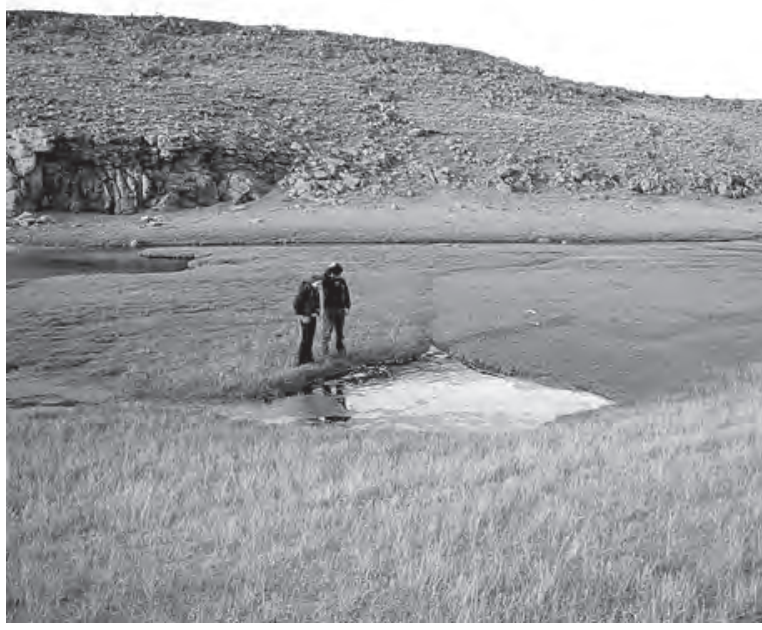

Fig. 4. Emplazamiento de Bye Beee! Al fondo puede observarse el curso principal del río Chico.

gura 4). La misma se encuentra colmatada de agua debido a que está conectada por canales al curso principal del río. En este locus, denominado "Bye beee!" hemos encontrado un depósito rico en huesos formado principalmente por especies introducidas y, en menor medida, especies nativas, tales como zorro gris (Dusicyon griseus) y colorado (D. culpaeus), chingue (Conepatus humboldtii), Ctenomys sp. y ñandú (Pterocnemia pennata). La aplicación de modelos de circulación de huesos en medios fluviales (Gutiérrez y Kaufmann 2007) así como la comprensión de los procesos tafonómicos actuales que operan en la cuenca del río y la evidencia tafonómica registrada en los huesos, nos han permitido inferir que la acumulación de este conjunto de vertebrados se relaciona principalmente con crecidas del río. En suma, que este rasgo funciona como una trampa que capturaría huesos sueltos antes que animales completos.

Los muestreos subsuperficiales mediante pruebas de barreno también estuvieron orientados a la búsqueda y detección de depósitos arqueológicos y/o tafonómicos en antiguos meandros semicolmatados ubicados en ambas márgenes del río Chico, independientemente de encontrar horizontes antiguos enterrados. La idea era reconocer si también habia huesos enterrados en esos rasgos. El único locus que contenía restos faunísticos (Locus C) se ubica sobre la margen izquierda del río ${ }^{3}$ y corresponde a

3 Ubicado en UTM: 19F 427240 / 4233547. 


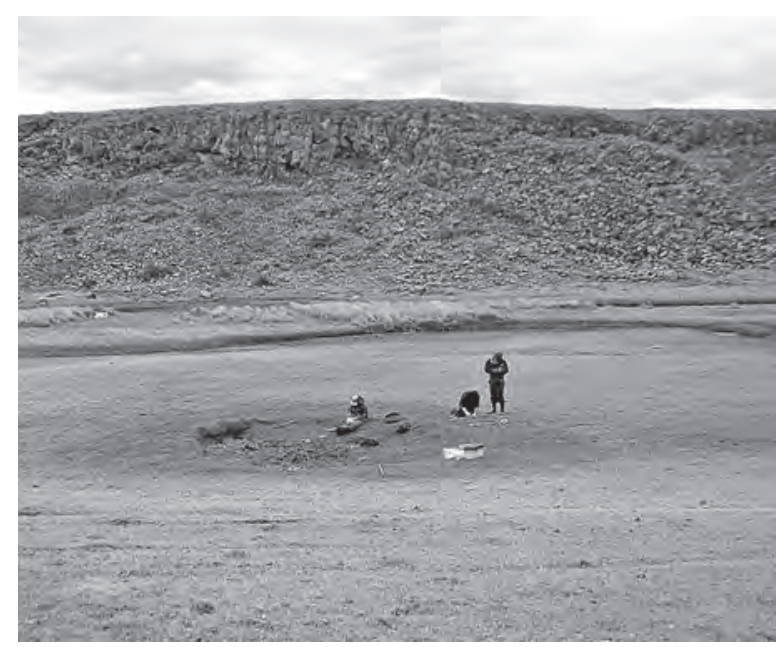

Fig. 5. Locus C colmatado de sedimentos. Nótese atrás el curso principal del río Chico.

una depresión de 6,6 x 5,3 metros (Figura 5). Dentro de la misma se realizaron seis pruebas de barreno emplazadas aleatoriamente. Los restos recuperados en los diferentes muestreos son escasos e incluyen principalmente restos de fauna introducida como oveja y, en menor número, caballo, únicamente detectado en el muestreo 4. En todos los muestreos profundizamos hasta el antiguo fondo de río, formado por clastos y gravas lo que, en la mayoría de los casos, constituyó un límite para alcanzar una profundidad mayor.

\section{Hallazgos en los escoriales}

En cuanto a los sitios prospectados y detectados en el escorial del Arctotherium, en el ámbito de las trampas secas, resulta interesante el hallazgo de dos burbujas subterráneas y un tubo de lava. Estos rasgos subterráneos en general son cavidades cerradas donde la única vía de acceso es a través del techo y donde el ingreso de animales -voluntario o no- implica una caída vertical que, en algunos casos, supera los 10 metros. Por esta razón, estos rasgos actúan como trampas, ya sea inhibiendo el escape y produciendo la muerte de los animales que ingresan a ellas. Los tres sitios trabajados -Anaqueles de la Angustia, Arcadis de la Esperanza y Trampa Mala Cueva- efectivamente funcionaron como trampas para algunos animales que cayeron en su interior, especialmente ovejas y carnívoros pequeños. Si bien estos sitios tienen rasgos y faunas en común, son muy diferentes entre sí. Trampa Mala Cueva (19 F 43419 $\mathrm{E}, 4235361 \mathrm{~N})$, que es un tubo de lava que alcanza una profundidad de 13 metros, no sólo funcionó como trampa para animales sino que también fue utilizado por cazadores humanos, probablemente con fines rituales (Figura 6). En este sitio, de muy difícil acceso, se efectuó un sondeo pequeño que mostró un contexto de depositación caracterizado por la presencia de una densa capa de ocre, un fogón pequeño -con una muestra de carbón que arrojó una antigüedad de $660 \pm 40$ AP (Beta-259595)- y piezas líticas confeccionadas sobre dos materias primas -calcedonia y obsidiana verde- que son poco frecuentes entre los grupos de cazadores terrestres surpatagónicos del Holoceno (San Román y Martin en prep.). Entre las piezas de calcedonia se destacan cinco bifaces grandes, semejantes a los recuperados en Morro Philippi (Argentina) en un contexto funerario (Ortiz Troncoso 1973). Las piezas de obsidiana verde, con procedencia en algún sector cercano al mar de Otway (Morello et al. 2004), corresponden a núcleos, lascas y una punta de proyectil.

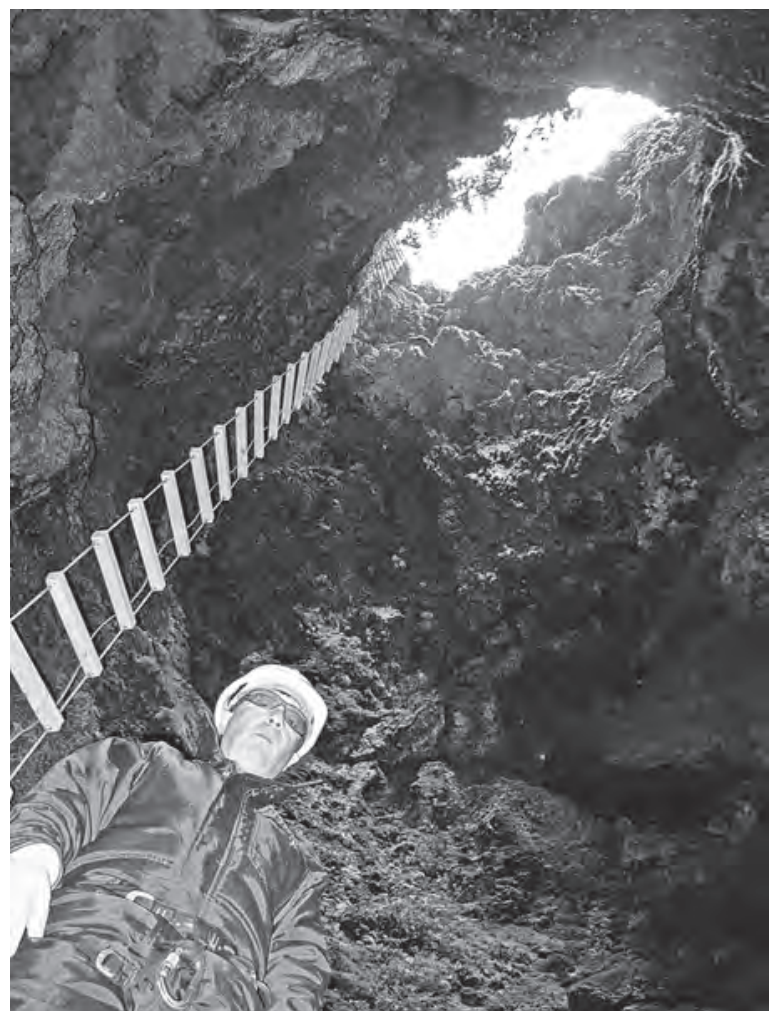

Fig. 6. Trampa Mala Cueva. Se destaca la entrada, formada a partir del colapso del techo. 
El sitio Anaqueles de la angustia (19F 432448 E, 4235387 N) es una burbuja subterránea de aproximadamente 12,80 metros de largo por 6,30 metros de ancho (Figura 6), que parece haber funcionado como una trampa para pequeños mamíferos, principalmente cánidos, pero también ha funcionado como una madriguera de puma, a juzgar por la presencia de grandes marcas de dientes sobre los escasos huesos de guanacos -que consideramos transportados- y por la presencia de excrementos de éste félido. Se destaca la ausencia de restos culturales.

La cronología de este sitio corresponde al Holoceno Tardío. Efectivamente, se fecharon restos de dos taxones diferentes, ambos procedentes de los niveles estratigráficos más profundos. Uno de estos, un molar superior de guanaco, fue fechado en $790 \pm 40$ AP (Beta-252911), mientras que un calcáneo de zorro colorado arrojó una antigüedad de $750 \pm 40$ AP (Beta- 252912) (San Román y Martin en prep.).

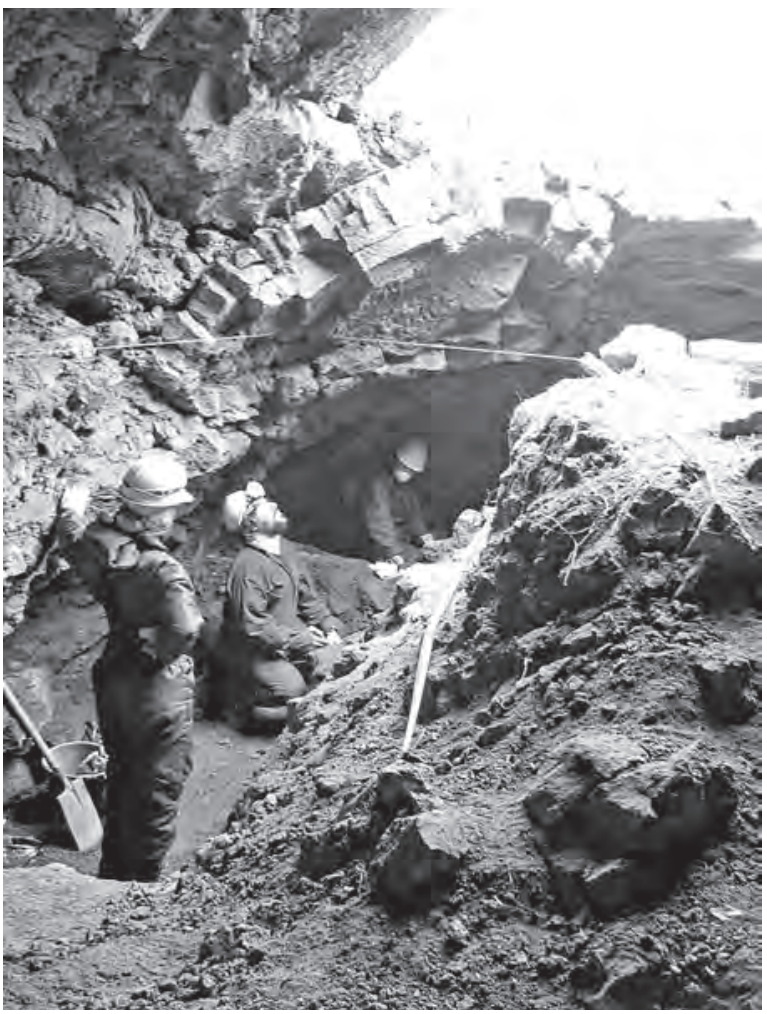

Fig. 7. Anaqueles de la Angustia en proceso de excavación.
El sitio Arcadis de la esperanza (19 F 428583 E, 4237138 N), una burbuja subterránea de dimensiones mayores a Anaqueles de la angustia, se caracteriza por una gran cantidad de carcasas de oveja, probablemente acumuladas por personal de la estancia durante la limpieza de los campos que suelen efectuar despues de la muerte invernal del ganado ovino. La fauna nativa está representada principalmente por carnívoros, aunque también se registaron huesos sueltos de guanaco y ñandu. Además destacamos la presencia de carcasas momificadas de pequeños carnívoros como chingues y zorros grises y elementos sueltos de pumas. En esta burbuja también recuperamos algunos artefactos líticos, pero los mismos han ingresado por gravedad desde un alero cercano que presenta restos arqueológicos en superficie y que se encuentra localizado a pocos metros, por encima de la boca de entrada de la burbuja,

Finalmente, se encuentran en realización numerosos análisis. Estos incluyen estudios de ADN, de ecología isotópica y cronológicos sobre muestras

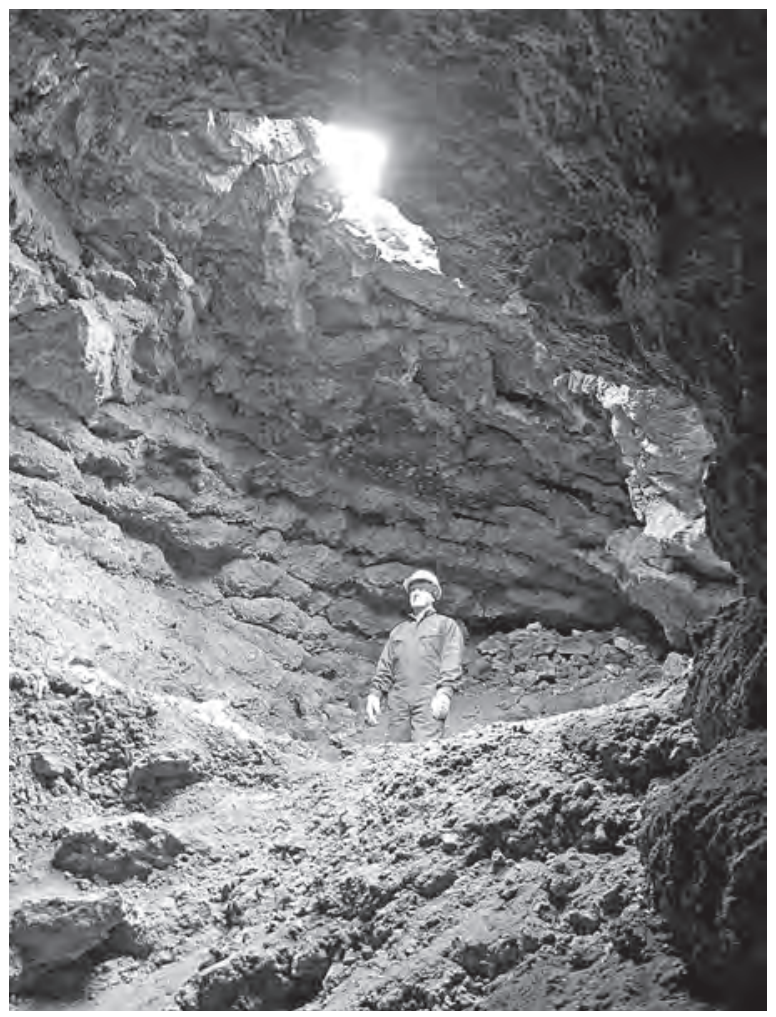

Fig. 8. Arcadis de la Esperanza. 
óseas y sedimentos procedentes de cueva de los Chingues y cueva del Puma que servirán, entre otras cosas, para reevaluar la taxonomía faunística y temas relacionados con la extinción pleistocena. Estos trabajos se realizan dentro de un programa de colaboración con la Universidad de Adelaide, Australia (ver Weinstock et al. 2005, Orlando et al. 2008). También se encuentran en realización estudios del material arqueológico, nuevos análisis radiocarbónicos para complementar los ya obtenidos y estudios más detallados de turbas, polen y otros sedimentos.

\section{DISCUSIÓN}

Los trabajos efectuados en sitios más usuales como cuevas y aleros, respaldan que en Pali-Aike la ocupación humana tiene una profundidad temporal adecuada para encontrar restos antiguos a cielo abierto. Esto ha resultado avalado por nuestra obtención de fechas radiocarbónicas basales para turberas pleistocenas en el río Chico y río Gallegos Chico [ver más abajo], las que claramente muestran la disponibilidad de espacios pertinentes de muestreo de la edad adecuada fuera de las cuevas.

De todas maneras, en general, los hallazgos de concentraciones de huesos son poco frecuentes a cielo abierto. Esta situación actual respalda la dificultad de detectar yacimientos finipleistocenos de estas características.

Examinando los casos actuales a través de trabajos tafonómicos enfocados a evaluar la "lluvia actual de huesos" en el sentido de Borrero (2001), encontramos que las tasas de depositación de animales autóctonos, actualmente ubicuos en el área de Pali-Aike, tales como guanacos o zorros parecen ser muy bajas en los antiguos meandros actualmente colmatados del río. Por lo tanto, y a juzgar por los registros conocidos de fauna extinta procedentes de cuevas, donde los restos no aparecen en grandes cantidades, podemos asumir que la tasa de depositacion de fauna extinta ha sido muy baja a nivel regional, debiendo estar éstos restos infrarepresentados en este tipo de registros a cielo abierto.

La única depresión formada en un antiguo meandro del río y actualmente colmatada de agua es, hasta el momento, el único rasgo que parece concentrar restos faunísticos (Bye beee!). Una vez más, en este caso, podemos ver que la fauna autóctona está infrarepresentada en relación a la actual. Esto tambíen estaría indicando bajas tasas de depositación de los huesos de esos animales en la actualidad. Sin embargo, creemos que la representación taxonómica, más rica en la cavidad colmatada de agua que en los meandros colmatados de sedimentos, está afectada por procesos colectores de huesos que resultan en un registro faunístico que presenta mayor riqueza taxonómica y anatómica. En otras palabras, estos rasgos, serían los concentradores de huesos en un medio fluvial, así como lo son las cuevas en las grandes extensiones entre cursos fluviales.

Pero, más allá de hallazgos concretos, uno de los temas básicos de nuestra investigación es el de redimensionar potenciales nichos carroñeros humanos. Los registros actualísticos muestran que las trampas "secas" tienen un potencial mayor de capturar animales completos, a diferencia de las trampas topográficas del río Chico, que parecen capturar principalmente restos sueltos depositados en la planicie de inundación del río. Si usamos esta evidencia para modelar casos del pasado, podríamos conjeturar que las trampas secas -que hoy forman un nicho carroñero para carnívoros pequeños - podrían potenciar un nicho carroñero para humanos (San Román y Martin en prep.). En cuanto a las trampas húmedas, el hallazgo del sitio Bye beee!, una cavidad asociada a un antiguo meandro del río, remite a los hallazgos de Pomi y Scanferla (2008) en el río Quequén Grande, Argentina, de un modo tafonómico característico de marmitas en cursos fluviales. Debe enfatizarse aquí que en Patagonia la definición de un nicho carroñero puede tener mayor amplitud en una situación invernal. Un trabajo tafonómico efectuado en Torres del Paine (Borrero et al. 2005) mostró que el invierno es adecuado para que los pumas que cazan guanacos produzcan un nicho carroñero, al mostrar la abundancia de carcasas de guanacos parcialmente consumidas generada por estos carnívoros, con el agregado de que la condición invernal extiende el lapso de utilidad de esos restos. Efectivamente, de manera comparativa hemos podido observar que, en principio, las carcasas de guanacos depositadas en invierno permanecen con carne durante un período mayor.

Por otra parte, todas las situaciones registradas en las trampas secas también enfatizan la importancia de las condiciones invernales. Como pudimos ver en un caso (Arcadis de la Esperanza), 


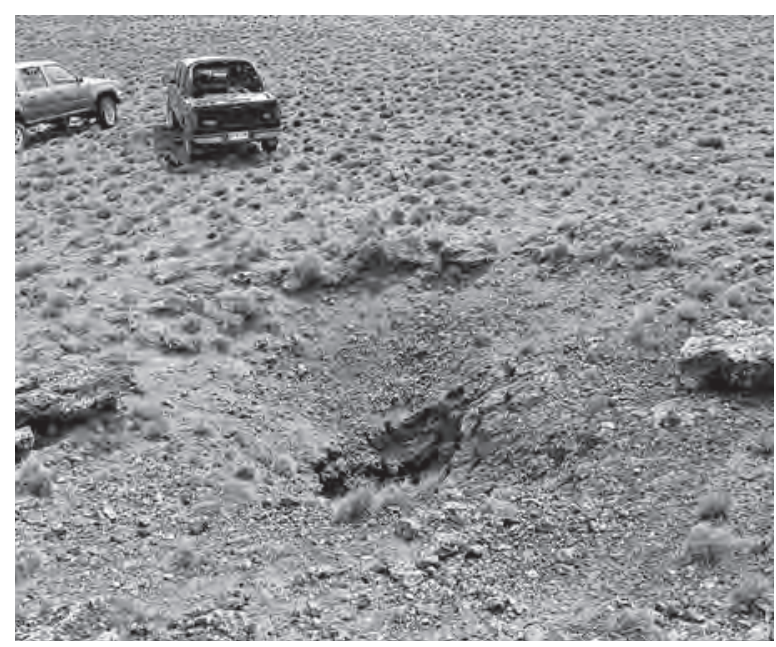

Foto 9. Entrada de Arcadis de la Esperanza. Se destaca la pronunciada pendiente hacia la misma.

la boca de entrada suele estar cubierta de nieve en el invierno y es muy difícil de detectar, ya que sólo puede distinguirse una pequeña abertura ubicada en la parte más profunda de la boca de entrada (Alvarado, com. pers.) [Foto 9]. Las trampas que en su interior presentan un montículo pronunciado, ya sea formado por sedimentos o por restos de animales que cayeron en estas, sirven como plataformas para la entrada y salida de algunos animales -principalmente carnívoros- que, en época invernal, se incrementa por la acumulación de nieve (Alvarado, obs. pers). En otras palabras, en época invernal estos sitios pueden no siempre funcionar como verdaderas trampas. Sin embargo, esto depende del tamaño corporal y la destreza o habilidad del animal para escapar de esa situación, por lo que poco ha de aplicar a herbivoros grandes (White et al. 1984).

En suma, los estudios tafonómicos naturalistas y las observaciones del registro indican que las trampas subterráneas de Pali-Aike muestran la presencia de pequeños carnívoros como mustélidos y zorros y evidencias de sus actividades. Si bien aún no conocemos bien los resultados de la actividad de zorrinos sobre carcasas de animales, ya hemos inferido su acción sobre restos humanos (Martin 2006). Para zorros grises disponemos de buena información sobre las actividades de carroñeo sobre restos de guanacos y ovejas (Borrero 1988, Borrero et al. 2005, Martin 2006). Las implicancias que tienen las actividades de carroñeo de zorros para las acumulaciones en las trampas de Pali-Aike son que, independientemente de la oferta de carne que estas trampas hayan creado, constituyeron un nicho carroñero para estos pequeños carnívoros. Existen otros casos de trampas que han presentado el mismo funcionamiento, como es el caso de las trampas Moonshiner y Middle Butte, en Idaho (USA) (White et al. 1984).

Lo dicho permite reevaluar los sitios ya conocidos a partir de la nueva evidencia generada en cada una de las áreas. En otras palabras, el reconocimiento de un rango más amplio de situaciones de depositación arqueológica y paleobiológica al aire libre, con un mejor conocimiento de la geografía en tiempos de la Transición, permite comprender mejor las diferentes poses estructurales de cazadoresrecolectores humanos a través del tiempo. Hemos presentado indicaciones acerca de la factibilidad de un nicho carroñero que, al ser particularmente sensible a condiciones invernales, resulta apropiado para generar modelos para los momentos más fríos que el actual correspondiente a fines del Pleistoceno (McCulloch et al. 2005). En otras palabras, aquellos ambientes muy fríos de fines del Pleistoceno comenzaron a ser ocupados por cazadores que pudieron tomar ventaja de la utilización de alimento inerte conservado por el frío en una variedad de situaciones. Estas tácticas, para las que hay inclusive registros históricos (Rogers 2002) pudieron resultar cruciales para las primeras ocupaciones humanas.

En un plano regional, comenzamos a evaluar el uso del espacio fuera de las cuevas y aleros, para contrarrestar la distorsión creada por la tendencia a excavar ese tipo de emplazamientos. También la evidencia paleoambiental -con pequeñas ventanas de información arqueológica y paleobiológica- obtenida en los barrenados contribuye a estos fines ${ }^{4}$. Con toda esta información buscamos considerar el grado de complementariedad entre los distintos tipos de sitios. En pocos casos ha podido obtenerse un registro variado y complementario relacionado con el uso de espacios acotados para fines del Pleistoceno, pues las condiciones de preservación suelen atentar contra esto. Pero, si se usan evidencias puntuales

4 Este proyecto se complementa con un proyecto paleoecológico dirigido por Charly French (Universidad de Cambridge) en el que se busca establecer una nueva secuencia polínica y estratigráfica para la región de Pali-Aike focalizada en la cueva Fell y alrededores (ver French y Scaife 2009). 
como las que nos proporcionan los barrenados o los registros esperables en trampas secas, dentro de un marco que considera la dinámica ambiental y sus cambios a través del tiempo, es posible acercarse a esa situación.

Si comparamos la evidencia osteológica recuperada en cueva Fell (Emperaire et al. 1963, Poulain Josien 1963, Bird 1988, Martin 2007) con la de la planicie aluvial del río frente a la misma, vemos que la cantidad de hallazgos en cada uno de estos loci es bien diferente. Cueva Fell presenta un registro faunístico muy rico, mientras que en la planicie del río se detectaron sólo dos especímenes con cronologia del Holoceno temprano del enterrados a cielo abierto. La presencia de manganeso en algunos huesos de los niveles inferiores de la cueva Fell, asi como la presencia de sedimentos laminados también en los niveles inferiores, sugieren antiguas crecidas del río (Bird 1988, French, com. pers.), que pudieron estar erosionando depósitos arqueológicos o produciendo una modificación en la disposición de los mismos. Los depósitos sedimentarios que conforman los niveles inferiores de la cueva, tan abundantes en presencia arqueológica, parecen no estar representados fuera de la misma. Esta evidencia, sumada a la mencionada más arriba y a la escasez de restos enterrados a pocos metros de la cueva, indicaría procesos erosivos intensos a fines del Pleistoceno en la planicie aluvial del río. En suma, pudieron darse condiciones adecuadas para que los restos se depositen, entierren y preserven a largo plazo, pero el dinamismo propio del río ha hecho que el registro sea muy elusivo. Entonces, independientemente de la frecuencia de hallazgos en distintos loci, es este conocimiento generado acerca de las condiciones bajo las cuales es esperable encontrar depósitos de determinada edad y en determinados sectores del espacio lo que constituye la base de una evaluación verdaderamente regional del registro. Entendemos que esta es información crucial para una evaluación tafonómica que pretenda funcionar en escala regional.

Por otra parte resulta claro que la investigación puede avanzar por el lado de producir resultados paleoecológicamente significativos. Estos resultados van más allá de la identificación de eventos tales como la formación de turbas horizontalmente extensivas o la depositación de tefras de procedencia lejana, ambos relevantes para comprender la ecología regional a fines del Pleistoceno. En este caso las in- vestigaciones estarían indicando que el río Chico, en las inmediaciones de la cueva Fell -y probablemente a lo largo de todo su cauce-, ha sido un ambiente muy dinámico, a juzgar por la discontinuidad existente entre depósitos de turbas y tefras que sugiere procesos erosivos quizá masivos en algunos sectores del río, informándonos también que las expectativas de encontrar señales ocupacionales en cotas bajas pericosteras son bajas.

El contexto paleoambiental de Pali-Aike, a diferencia de lo que ocurre con algunos sitios finipleistocenos de Norteamérica (Haynes 1985, 2002), nos permite sostener que los humedales no actuaron como concentradores de faunas en el pasado en esta área, dado que el agua no ha sido un recurso limitante aquí. De manera que, aunque estos sectores del espacio pueden producir hallazgos, no deberíamos esperar que los concentren. En un plano regional los contextos y tasas de depositación de faunas pleistocenas debieron ser muy bajos a diferencia de lugares puntuales del espacio como cuevas y/o aleros por un lado -donde a partir de un momento dado comenzaron a ser controlados por humanos- y trampas potenciales por el otro. Por otra parte, las turbas de Pali-Aike, en escala regional, tienen oportunidades para preservar registros fósiles debido a que se presentan en forma de mosaico, en condiciones regidas por la distribución de agua. De esta manera, los cursos de agua y cuerpos lacustres han presentado acumulaciones de turba en diferentes etapas de su desarrollo. Esta situación topográfica lleva a que haya habido mayor cantidad de condiciones para interceptarlas en el pasado por humanos y fauna.

En suma, Pali-Aike parece mostrar un ambiente altamente dinámico, con importantes procesos erosivos actuando en torno al río Chico a lo largo de miles de años. Por otro lado la historia geológica de Pali-Aike generó una amplia variedad de sitios con potencial de trampas, cuya disponibilidad varió a través del tiempo en función del colapso del techo y otros cambios.

\section{CONCLUSIONES}

Han sido importantes una serie de resultados tafonómicos actuales. Una observación es que, en general, las trampas secas capturan huesos y animales completos, mientras que las formadas en el rio Chico parecen capturar principalmente huesos sueltos. A 
partir de estas observaciones, y en conjunto con algunos de los resultados fósiles aquí presentados, comenzamos a comprender algunas variaciones en el potencial de acumulación y preservación de materiales óseos.

Podemos decir que en Pali-Aike se dan las condiciones adecuadas para que existan y se puedan preservar restos óseos en turberas antiguas actualmente enterradas. Una tendencia observada en los muestreos efectuados con barrenos es que algunas estratos sedimentarios se expresan discontinuamente (especialmente tefras y turberas), implicando que el ambiente del río ha sido muy dinámico, por lo que la expectativa de encontrar depósitos antiguos no siempre es alta. Es posible que algunos de estos depósitos se erosionaran, por lo que es evidente que la detección de este tipo de evidencias requiere un mayor esfuerzo de muestreo. Sin embargo, el hallazgo de materiales, bajo estas condiciones, constituye una entrada inusual y de interés al registro arqueológico de la región. En cuanto a preservación, hemos podido observar sedimentos con alto contenido orgánico en los barrenados, con macrovegetales preservados fechados en ca. 10.000-14.000 AP, pero los únicos restos óseos recuperados, en un contexto que sugiere una cronología del Pleistoceno Tardío-Holoceno Temprano, presentan una preservación regular.

Las trampas secas, por su lado, muestran hasta el momento menor profundidad temporal, acotada al Holoceno tardío. De todas maneras, más allá de la obtención de conjuntos faunisticos, la exploración de las trampas nos permitió recuperar un conjunto arqueológico inusual en Trampa Mala Cueva. Estas evidencias nos permiten afirmar que existen mecanismos que operan como trampas naturales en contextos húmedos y secos que tienden a acumular faunas y restos arqueológicos, lo que constituye un gran avance respecto a nuestro conocimiento de los procesos que han actuado $y$ actúan durante el Holoceno.

El hallazgo de Trampa Mala Cueva, por otra parte, estaría indicando que los antiguos pobladores de Patagonia disponían de una amplia variedad de técnicas dentro de su repertorio cultural, las que les permitieron afrontar situaciones complejas tales como acceder a ciertos sectores del espacio que hoy nos resultan difíciles de abordar a pesar de la tecnología disponible. Otras trampas secas, como Anaqueles de la Angustia pueden ser vistas como entregando resultados puramente tafonómicos, en tanto que Arcadis de la Esperanza es semejante, con el agregado de un componente cultural que parece estar redepositado. Esto último no es una circunstancia inusual, recordando, entre muchos otros, el único artefacto recuperado en el sitio paleontologico Shield Trap Cave (Oliver 1989), o los casos aislados de artefactos en madrigueras de hienas (Villa and Soressi 2000, Stiner 2004). Lo que esta última información subraya, es que raramente los depósitos fósiles nos entregarán una marca unívoca, que es usual que se produzcan palimpsestos y que ningún esfuerzo destinado a desentrañarlos será suficiente.

\section{AGRADECIMIENTOS}

Los trabajos fueron financiados por el Proyecto FONDECYT 1070709. Queremos expresar nuestro agradecimiento a los propietarios de la Estancia Brazo Norte, Juan Strello y Mirko Zec, así como a la señora Peggy Fell e hijas por su apoyo y amabilidad. A nuestros compañeros de trabajo y amigos Pedro Cárdenas, Omar Reyes, Valentina Trejo, Ismael Martínez, Patricia Campán, Luis A. Borrero, Ramiro Barberena, Flavia Morello y Gabriel Bahamonde. Al equipo Roca Base (Armando Iglesias, Oscar Mancilla, Américo Alvarez, Pedro Cárdenas y Erik Lukoviek) por los trabajos de "excavación" en Arcadis de la Esperanza. A Nestor Alvarado por su hospitalidad. Finalmente, a Luis A. Borrero por su lectura crítica.

\section{BIBLIOGRAFÍA}

AGENDBRDAD, L.D. 1984. Hot springs, South Dalota: Entrapment and taphonomy of columbian mammoth. Quaternary extinctions a prehistoric revolution (Eds. P.S. Martin y R. C. Klein), pp. 113-127, the University of Arizona press.

ARSUAGA, J. L., I. MARTÍNEZ, A. GRACIA, J. M. CARRETERO, C. LORENZO y N. GARCÍA. 1997. Sima de los Huesos (Sierra de Atapuerca, Spain) The site. Journal of Human Evolution 33: 109-127.

AULER, A.S., L. B. PILÓ, P. L. SMART, X. WANG, D. HOFFMANN, D. A. RICHARDS, R. L. EDWARDS, W. A NEVES y H. CHENG. 2006. U-series dating and taphonomy of Quaternary vertebrates from Brazilian caves. Palaeogeography, Palaeoclimatology, Palaeoecology 240: 508-522. 
BARBERENA, R., F. M. MARTIN y L. A. BORRERO. 2007. Estudio biogeográfico de conjuntos faunísticos: sitio Cóndor 1 (Pali Aike). Arqueología de Fuego-Patagonia. Levantando piedras, desenterrando huesos... Develando arcanos. Editado por: F. Morello, A. Prieto, M. Martinic y G. Bahamondes, pp. 139-150. Ediciones CEQUA, Punta Arenas, Chile.

BINFORD, L.R. 1981. Bones. Ancient Men and Modern Myths. New York: Academic Press.

BIRD, J. 1988. Travels and Archaeology in South Chile. Iowa University Press, Iowa City.

BONARELLI, G. 1917. Tierra del Fuego y sus turbas. Anales del Ministerio de Agricultura, Sección Geol. XII, 3, Buenos Aires.

BORRERO, L. A. 1986. La Economía Prehistórica de los habitantes del Norte de la Isla Grande de Tierra del Fuego. Tesis Doctoral inédita. Universidad de Buenos Aires.

BORRERO, L. A. 1988. Estudios tafonómicos en Tierra del Fuego: su relevancia para entender procesos de formación del registro arqueológico. Arqueología Contemporánea Argentina: 13-32. Ediciones Búsqueda.

BORRERO, L. A. 1999. The Prehistoric Exploration and Colonization of Fuego-Patagonia. Journal of World Prehistory 13 (3): 321-355.

BORRERO, L. A. 2001. Regional Taphonomy: Background noise and the Integrity of the Archaeological Record, en Ethnoarchaeology of Andean South America. Contributions to Archaeological Method and Theory, editado por L. Kuznar. Pp. 243-254. Ann Arbor: International Monographs in Prehistory.

BORRERO, L. A. 2009. The elusive evidence: the archaeological record of the South American extinct megafauna. American megafaunal extinctions at the end of the Pleistocene. Editado por G. Haynes, pp.145-168. Springer, Reno.

BORRERO, L. A., F. M. MARTIN y J. VARGAS. 2005. Tafonomía de la interacción entre pumas y guanacos en el Parque Nacional Torres del Paine, Chile. Magallania 33(1): 95-114.

BORRERO, L., R. BARBERENA, F. MARTIN y K. BORRAZZO. 2007. Collapsed Rockshelters in Patagonia. On Shelter's Ledge: Histories, Theories, and Methods of Rockshelter Research, editado por M. Kornfeld, Sergey Vasil'ev y Laura Miotti, pp. 135-139. BAR International Series, Oxford.

CORBELLA, H. 1999. Dataciones radimétricas en Pali Aike, Patagonia austral. Actas del XIV Congreso Geológico Argentino II: 265-268. Salta.
-2002. El campo volcano-tectónico de Pali Aike. En: Geología y Recursos Naturales de Santa Cruz. Relatorio del XV Congreso Geológico Argentino, editado por: M. J. Haller 1-18:285-301.

D' ORAZIO, M., S. AGOSTINI, F. MAZZARINI, F. INNOCENTI, P. MANETTI, M. J. HALLER y A. LAHSEN. 2000. The Pali Aike Volcanic Field, Patagonia: slab-window magmatism near the tip of South America. Tectonophysics 321:407-427.

EMPERAIRE, J., A. LAMING y H. REICHLEN. 1963. La grotte Fell et autres sites de la région volcanique de la Patagonia chilienne. Journal de la Société des Américanistes Nouvelle Série 52:167-254.

FRENCH, C. y R. SCAIFE. 2009. Fell's Cave and the associated Rio Chico, Pali Aike, southern Patagonia, Chile:The geoarchaeological and palynological field assessment. Informe de avance segundo año de ejecución Proyecto FONDECYT 1070709 "Trampas naturales y humedales: explorando la variabilidad del registro arqueológico y tafonómico de Patagonia Meridional", pp. 70-77.

GIFFORD-GONZÁLEZ, D. P. 1989. Modern analogues: developing an interpretative framework, en Bone Modification. Editado por R. Bonnichsen y M. Sorg, pp. 43-52. Orono: Center for the Study of the First Americans.

GÓMEZ OTERO, J. 1989-1990. Cazadores tardíos en la zona fronteriza del paralelo $52^{\circ} \mathrm{S}$. I. El paraje de Juni Aike. Anales del Instituto de la Patagonia (Serie Ciencias Sociales) 19: 47-71.

GOULD, S.J. 2002. The Structure of Evolutionary Theory. Cambridge: The Belknap Press of Cambridge University Press.

GUTIÉRREZ, M. y C. KAUFMANN. 2007. Criteria for the Identification of Formation Processes in Guanaco (Lama guanicoe) Bone Assemblages in Fluvial-Lacustrine Environments. Journal of Taphonomy 5(4): 151-176.

HAYNES, G. 1985. On watering Holes, Mineral licks, Death, and predation" En: Environments and extinctions: Man in late Glacial North America. Editado por Mead and D. Meltzer. Center for the study of early Man. Orono.

HAYNES, G. 2002. The catastrophic extinction of Noth American mammoth and mastodonts. World Archaeology 33 (3): 391- 416.

HEUSSER, C.J. 2003. Ice Age southern Andes: a chronicle of paleoecological events, Elsevier, Amsterdam.

L'HEUREUX, G. L. 2008. La arqueofauna del campo volcánico Pali Aike. El sitio Orejas de Burro 1, Santa Cruz, Argentina. Magallania 36 (1): 65-78.

LULL, R. S. 1929. A remarkable ground sloth. Memoirs of the Peabody Museum of Yale University 3 (2): 1-39. 
MARTIN, F. M. 2006. Carnívoros y huesos humanos de Fuego-Patagonia. Aportes desde la Tafonomía Forense. Sociedad Argentina de Antropología, Buenos Aires.

MARTIN, F. M. 2007. Tafonomía y Paleoecología de la Transición Pleistoceno-Holoceno en Fuego-Patagonia. Interacción entre Poblaciones Humanas y de Carnívoros y su importancia como Agentes en la Formación del Registro Fósil. Tesis doctoral inédita. Facultad de Ciencias Naturales y Museo de la Universidad Nacional de La Plata.

MARTIN, F.M. 2008. Bone Crunching felids at the End of the Pleistocene in Fuego-Patagonia, Chile. Journal of Taphonomy 6(3-4): 337-372.

MARTIN, F.M. y L.A. BORRERO. 1997. A puma lair in Southern Patagonia: implications for the archaeological record. Current Anthropology 38: 453-461.

MARTIN, F.M. y L.A. BORRERO. 2004. Mundo Subterráneo. Regional Taphonomy at the Pali-Aike Lava Field, Santa Cruz, Argentina. Trabajo presentado al 69th Annual Meeting de la SAA en Montreal, MS.

MARTIN, F.M. y L.A. BORRERO. 2010. Mundo Subterráneo: Tafonomía regional en el Campo Volcánico Pali-Aike, Santa Cruz, Argentina. Arqueología de Pali Aike y Cabo Vírgenes (Santa Cruz, Argentina). Editado por L.A. Borrero y J. Charlin, pp. 55-80, CONICET-IMHICIHU, Buenos Aires.

MARTIN, F. M., A. PRIETO, M. S. ROMÁN, F. MORELLO, F. PREVOSTI, P. CÁRDENAS y L. BORRERO. 2004. Late Pleistocene Megafauna at Cueva del Puma, Pali-Aike Lava Field, Chile. Current Research in the Pleistocene 21:101-103.

MARTIN, F. M., L. A. BORRERO y M. SAN ROMÁN. 2010. World of volcanoes. Core samples, lava tubes and other traps information. Préhistoire del'Amérique, CTHS, France. Editeur Denis Vialou, MS.

MARTINDALE, A., B. LETHAM, D. MCLAREN, D. ARCHER, M. BURCHELL, B. R. SCHONE. 2009. Mapping of subsurface shell midden components through percussion coring: examples from the Dundas Islands. Journal of Archaeological Science 36: 1565-1575.

MASSONE, M. 1981. Arqueología de la región volcánica de Pali Aike (Patagonia meridional chilena). Anales del Instituto de la Patagonia 12: 95-124.

MASSONE, M. y E. HIDALGO. 1981. Investigaciones arqueológicas en el Alero Pali-Aike 2 (Patagonia Meridional Chilena). Anales del Instituto de la Patagonia 12: 125-140.

MCCULLOCH, R. D., C. J. FOGWILL, D. E. SUGDEN, M. J. BENTLEY y P. W. KUBIK. 2005. Chronology of the last glaciation in central Strait of Magellan and Bahía Inútil, southernmost South America. Geografiska Annaler 87A: 289-312.
MIOTTI, L. y SALEMME, M. 1999. Biodiversity, Taxonomic Richness and Generalist-Specialists economical systems in Pampa and Patagonia Regions, Southern South America. Quaternary International 53-54: 53-68.

MORELLO, F.; L. BORRERO, J. TORRES, M. MASSONE, M. ARROYO, R. MCCULLOCH, E. CALAS, M. LUCERO, I. MARTÍNEZ y G. BAHAMONDE. 2009. Evaluando el registro arqueológico de Tierra del Fuego durante el Holoceno temprano y medio. En: Arqueología de Patagonia: una mirada desde el último confín, editado por M. Salemme, F. Santiago, M. Álvarez, E. Piana, M. Vázquez y M.E. Mansur. 1075-1092 p. Editorial Utopías, Ushuaia.

MORELLO, F., M. SAN ROMÁN y A. PRIETO. 2004. Obsidiana verde en Fuego-Patagonia: distribución y estrategias tecnológicas. Contra viento y marea, Editado por M. T. Civalero, P. Fernández y G. Guráieb, pp. 149-165, INAPL, Buenos Aires.

MORENO, P.I., J.P. FRANÇOIS, R.P. VILLA-MARTÍNEZ y C.M. MOY. 2009. Millennial-scale variability in Southern Hemisphere westerly wind activity over the last 5000 years in SW Patagonia. Quaternary Science Reviews 28: 25-38

NAMI, H. G. 1999. Arqueología en la localidad arqueológica de Pali Aike, cuenca del río Chico. I. Las investigaciones arqueológicas. Praehistoria 3:189-201.

OCAMPO, C. y P. RIVAS. 2000. Nuevos fechados 14C de la costa norte de la isla Navarino, costa sur del canal Beagle, provincia Antartica chilena, Región de Magallanes. Anales del Instituto de la Patagonia (Serie Ciencias Humanas) 28: 197-214.

OLIVER, J. S. 1989. Analogues and site context: bone damages from Shield Trap Cave (24CB91) Carbon County, Montana, U.S.A., en Bone Modification. Editado por R. Bonnichsen y M. Sorg, pp. 73-98. Orono: University of Maine Center for the Study of the First Americans.

ORLANDO, L., D. MALE, M. T. ALBERDI, J. L. PRADO, A. PRIETO, A. COOPER, C. HA“NNI. 2008. Ancient DNA Clarifies the Evolutionary History of American Late Pleistocene Equids. J Mol Evol DOI 10.1007/ s00239-008-9100-x.

ORTIZ-TRONCOSO, O. 1973. Artefactos de silex de una tumba de Morro Philippi, valle medio del río Gallegos. Anales del Instituto de la Patagonia, Vol IV, Números 1 y 3 , pp. 131-139.

POMI, L. H. y C.A. SCANFERLA. 2008. Tafonomía sobre asociaciones de vertebrados registradas en trampas fluviales de la Región Pampeana (Buenos Aires, Argentina). Estudios Geológicos 64(2): 187-196. 
POULAIN-JOSIEN, T. 1963. La Grotte Fell. Ètude de la faune. Journal de la Société des Américanistes 52:230-254.

PRIETO, A. 1997. Algunos resultados de los trabajos arqueológicos en Juni-Aike 2. Anales del Instituto de la Patagonia (Serie ciencias humanas) 25: 137-146.

ROGERS, T. 2002 [1879]. Expedición a la parte austral de la Patagonia por el Teniente Segundo de la Armada de Chile Señor Juan Tomás Rogers. En Marinos de a caballo. Exploraciones terrestres de la Armada de Chile en la Patagonia austral y la Tierra del Fuego. 1877-1897, editado por M. Martinic, pp. 19-60, Universidad de Magallanes y Universidad de Playa Ancha.

SANGUINETTI DE BÓRMIDA, A. C. 1976. Excavaciones prehistóricas en la Cueva de las Buitreras. Relaciones de la Sociedad Argentina de Antropología X: 271-292.

SAN ROMÁN y MARTIN, en preparación. Registros de trampas naturales de huesos en Pali-Aike.

SAN ROMÁN, M., F. MORELLO R. y A. PRIETO. 2000. Cueva de Los Chingues (Parque Nacional Pali-Aike), Magallanes, Chile. Historia natural y cultural I. Anales del Instituto de la Patagonia (Serie Ciencias Humanas) 28:125-143.

SAN ROMAN, M. y A. PRIETO. 2004. (Dis)continuidad en el uso de la obsidiana verde entre poblaciones de adaptación marítima del mar de Otway y Estrecho de Magallanes. Contra viento y marea. Arqueología de Patagonia, ed. Por M. Civalero, P. Fernández y A. Guráieb, pp. 571580. INAPL y SAA, Buenos Aires.

SKEWES, M.A. 1978. Geología, petrología, quimismo y origen de los volcanes del área de Pali-Aike, Magallanes, Chile. Anales del Instituto de la Patagonia 9: 95-106
STERN, C.R. 2008. Holocene tephrochronology record of large explosive eruptions in Southernmost Patagonian Andes. Bulletin Volcanology. DOI 10.1007/s00445-007-0148-z.

STINER, M.C. 2004. Comparative ecology and taphonomy of spotted hyenas, humans, and wolves in Pleistocene Italy. Revue de Paléobiologie, Genève 23(2): 771-785.

STINER, M.C., G. ARSEBUK y F.C. HOWELL. 1996. Cave Bears and Paleolithic Artifacts in Yarimburgaz Cave, Turkey: Dissecting a Palimpsest. Geoarchaeology 11: 279-327.

VILLA, P. Y M. SORESSI. 2000. Stone tools in carnivore sites: The case of Bois Roche. Journal of Anthropological Research 56: 187-215.

WANG, X. y L. MARTIN. 1993. Natural trap cave. National Geographic Research \& Exploration 9 (4): 422-435.

WEINSTOCK, J., E. WILLERSLEV, A. SHER, W. TONG, S. Y. W. HO, D. RUBESTEIN, J. STORER, J. BURNS, L. MARTIN, C. BRAVI, A. PRIETO, D. FROESE, E. SCOTT, L. XULONG y A. COOPER. 2005. Evolution, systematics, and phylogeography of pleistocene horses in the New World: a molecular perspective. PLOS Biology 3 (8):e 241.

WHITE, J.A., G. MCDONALD, E. ANDERSON y J.M. SOISET. 1984. Lava Blisters as Carnivore Traps. Special Publication Carnegie Museum of Natural History 8: 241-256.

WOLVERTON, S. 2001. Caves, ursids, and artifacts: A naturaltrap hypothesis. Journal o Ethnobiology 21(2): 55-72

WOLVERTON, S. 2006. Natural-trap ursid mortality and the Kurte'n Response. Journal of Human Evolution 50: 540-551. 